\title{
Raising International Discourse Rights in Translation and Interpreting Pedagogy
}

\author{
Dawn Fei-yue Tsang* \\ School of Foreign Languages, Beijing Institute of Technology, Zhuhai 519000, Guangdong Province, China
}

*Corresponding author: Dawn Fei-yue Tsang, dawndawntsang@126.com

Copyright: ( $) 2022$ Author(s). This is an open-access article distributed under the terms of the Creative Commons Attribution License (CC BY 4.0), permitting distribution and reproduction in any medium, provided the original work is cited.

\begin{abstract}
This research project aims at consolidating and revitalizing translation and interpreting pedagogy with dual emphasis on the cultural soft power and international discourse rights of China via emphasizing international competitiveness. In order to realize the significant needs of the current market requirements and the new era of China, this project proposes the "ICC" interpreting training model. It refers to the combination of intercultural communication competency with international competitiveness as the teaching and learning outcomes by means of integrating the following five components in the course content and the whole curriculum design: (1) interpreting competency - bilingual competence and interpreting skill-based training; e.g., short-term memory and note-taking; (2) national value - strengthening translation and the crucial roles and responsibilities of interpreter trainers and trainees in disseminating national culture; (3) expertise of subject matters equipping students with expertise for work field and meeting the market requirements; e.g., specific professional knowledge and jargons demanded by the tasks; (4) professional ethics and image - extra-linguistic knowledge emphasizing a translator's and an interpreter's professional code of conduct and ethics in a way that can establish the "iconic" image of a professional interpreter; e.g., confidentiality, posture, and appearance; (5) practical assessment - evaluation of students' performance in practical translation and interpreting opportunities and/or internship in organizations of various natures according to international standards. This research proposes a new training model to incorporate intercultural communication competency with international competitiveness. The significant role of interpreting pedagogy in contributing to a sound national name is investigated. The new "ICC" model that this research is proposing answers such a call for the significant role of raising cultural soft power and international discourse rights in China.
\end{abstract}

Keywords: Translation pedagogy; Interpreting pedagogy; International discourse rights of China; Intercultural competency; New translation training model

Online publication: January 13, 2022

\section{Introduction}

This research proposes to establish an "Intercultural Communication Competence + International Competitiveness" (ICC) interpreting training model to uplift students' intercultural communication competency and international competitiveness. The proposed model comprises of five essential elements: (1) interpreting competency; (2) national value; (3) expertise of subject matters; (4) professional ethics and image; (5) practical assessment. It targets at examining and comparing the teaching and learning outcomes as well as the distinctive pedagogy of ten major interpretation schools in China and around the globe. Indepth surveys and interviews with professional interpreters, interpreter trainers and trainees, as well as potential clients are conducted to consolidate interpreting pedagogy at higher institutions. The first expected 
research outcome is the strengthening of curriculum design for interpreting in terms of professionalism, professional knowledge, and professional standards. Secondly, it incorporates the most up-to-date teaching methodology to cultivate students with intercultural communication competency and international competitiveness. Finally, this research emphasizes the applicability and strategic development of interpreting with the ambition of building up a new training model for interpretation at higher institutions. This project aims at consolidating and revitalizing interpreting pedagogy with dual emphasis on intercultural communication competency and international competitiveness, ultimately to contribute to the cultural soft power and international discourse rights of China. In order to achieve this aim and to realize the market requirements as well as the significant needs in the new era of China, the "ICC" interpreting training model is proposed. It refers to the combination of intercultural communication competency with international competitiveness as the teaching and learning outcomes by means of integrating the following five components in the course content and the whole curriculum design: (1) interpreting competency bilingual competence and interpreting skill-based training; e.g., short-term memory and note-taking; (2) national value - strengthening the crucial roles and responsibilities of interpreter trainers and trainees in disseminating national culture; (3) expertise of subject matters - equipping students with expertise for the work field and meeting with the market requirements; e.g., specific professional knowledge and jargons demanded by the tasks; (4) professional ethics and image - extra-linguistic knowledge emphasizing an interpreter's professional code of conduct and ethics in a way that can establish the "iconic" image of a professional interpreter; e.g., confidentiality, posture, and appearance; (5) practical assessment - evaluation of students' performance in practical interpreting opportunities and/or internship in organizations of various natures according to international standards.

\section{Significance and research outcomes}

The rationale of establishing this "ICC" model is analyzed.

\subsection{Interpreting competency}

Interpreting refers to the instant exchanges of ideas and remarks, and therefore interpreting pedagogy is crucial to prepare interpreters in such a manner to exercise precise judgment and sharp aptitude in a matter of seconds in actual interpreting events. The most fundamental requirements are bilingual competency and interpreting skills.

\subsection{National value}

Interpreters bear the responsibility of bridging cultural inheritance and disseminating languages as well as cultures, in which this bridge must be built firmly and concretely ${ }^{[1]}$. According to the latest figures released by the Annual China Language Industry Report $2017^{[2]}$, 64\% of the translation corporations recorded that more than $50 \%$ of their businesses involved translating and interpreting Chinese into foreign languages, while $13 \%$ of the corporations recorded $80 \%$ to $100 \%$. It proves that China has transformed from a "western-culture importer" to a "Chinese culture exporter," thus reflecting the growing significant role of China in international discourse. In this sense, interpreters are active participators of "speaking out Chinese voice" and "telling Chinese stories well."

\subsection{Expertise of subject matters}

Based on the current research findings, the market requires translators and interpreters to equip themselves with professional knowledge of the tasks on top of excellent interpreting competency. 


\subsection{Professional ethics and image}

Interpreters symbolize the national name as their professional performance represents cultural soft power and influences the national image. Be it in commercial negotiation, diplomatic events, speeches, or conversations delivered by clients, the performance of interpreters, including their posture, demeanor, and appearance, would be evaluated by the audience on site. So far, this area seems to be a lacuna in interpreting pedagogy.

\subsection{Practical assessment}

By combining the aforementioned components, students are expected to be well trained and herein this research proposes to include both work simulation and actual practices for assessment purposes. The assessment criteria should be formulated by international standards, so that the students' performance and interpreting quality can and will be recognized internationally.

\subsection{Groundbreaking points}

This being so, this research proposes a new training model incorporating intercultural communication competency with international competitiveness. It investigates the significant role of interpreting pedagogy in contributing to a "sound" national name. Figure 1 shows the new "ICC" model that this research is proposing in answer to such a call for the significant role of raising cultural soft power and international discourse rights in China.

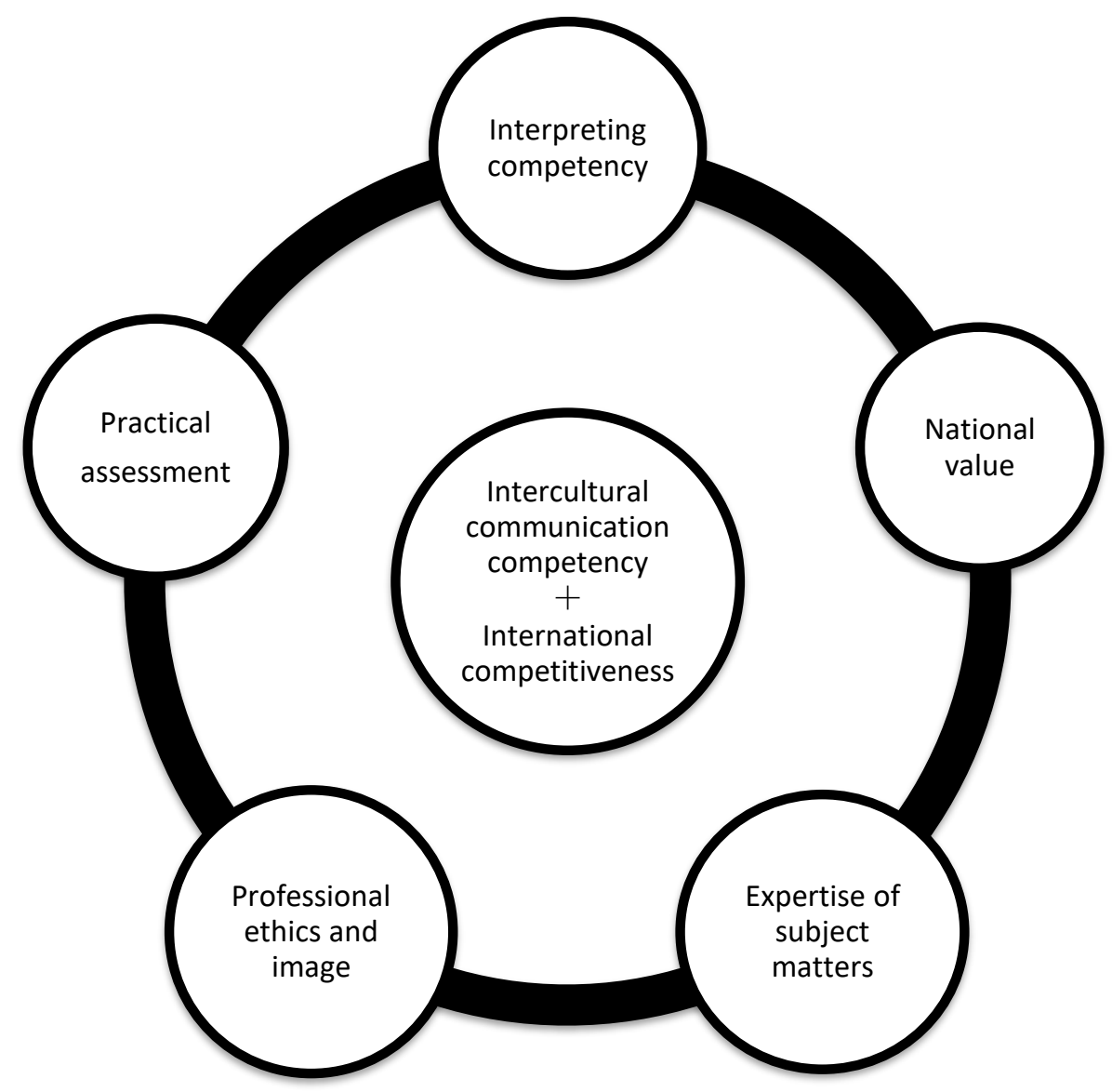

Figure 1. "ICC" model 


\section{Research background}

\subsection{National policy on exporting Chinese value}

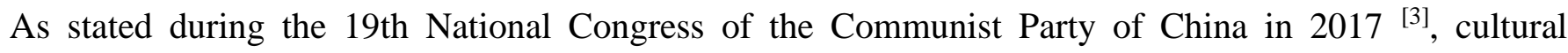
confidence represents a fundamental and profound force that sustains the development of a country and a nation. Since modern Chinese culture is rooted in fine traditional culture, it is mandatory to promote the creative evolution and development of the fine traditional Chinese culture as well as improve the country's capacity for international communication so as to tell China's stories well, present a true, multi-dimensional, and panoramic view of China, and enhance the country's cultural soft power. The focus of instilling national value into the curriculum design responds to the call of the new era. In order to develop a new teaching model, raising cultural value and cultural soft power shall be integrated into interpreting pedagogy, which is essential for raising China's international discourse rights. Yet there has been no mention in academia on how interpreting pedagogy can contribute to such an essential development. Therefore, in order to act upon national strategy and the latest development of China, a new teaching model of interpreting with national value is necessary.

\subsection{Translation curriculum}

Ample research on translation curriculum and pedagogy has been done. However, the emphasis has always been on written translation instead of interpreting. Liu Miqing implored that four components should constitute the foundation of the curriculum design for Bachelor of Translation and Interpreting (BTI) programmes: basic knowledge, an understanding of translation history, an understanding of translation theory, and practical translation skills ${ }^{[4]}$. Liao Qiyi stated that the curriculum design of translation courses has been unsystematic, in which it overemphasizes skill training but overlooks translation theories ${ }^{[5]}$. Jiang Qiuxia and Cao Jin analyzed the curriculum design of the BTI programmes delivered by fourteen mainland universities and concluded that the curriculum design is incomplete and unclear [6]. Zhong Weihe highlighted that three courses should be included in the curriculum design of BTI programmes: common knowledge courses, language courses, and interpreting skills courses ${ }^{[7]}$. In short, interpreting curriculum and interpreting pedagogy have rarely been mentioned per se in the development and analysis of BTI programmes despite " $\mathrm{T}$ " and " $\mathrm{I}$ " both exist; in addition, it seems that there is an imbalance in course proportion. This being so, emphasizing interpreting ("I") is the primary focus.

\subsection{Interpreting models}

At present, there are 252 Bachelor of Translation and Interpreting (BTI) programmes and 215 Master of Translation and Interpreting (MTI) programmes in China (China National Committee for Translation \& Interpreting Education 2017). It seems that teaching and learning interpreting is comparatively underemphasized as only four interpreting training models have been and are prevalent in China; i.e., Beijing Foreign Studies University (Beiwai Model), Shanghai International Studies University (Shangwai Model), Guangdong University of Foreign Studies (Guangwai Model), and Xiamen University (Xiada Model). Much research has been done on the framework and teaching methodology of these major interpreting schools; e.g., Professional Interpreting: Teaching, Learning and Researching by Liu Heping in 2017 and Methodology in Interpreting Studies by Zhong Weihe and other researchers in 2012. However, it still lacks a comprehensive study on the four models altogether and a comparison with major interpreting models in Taiwan and western countries. A parallel study on the teaching and learning outcomes of international competitiveness and intercultural communication competency among these major interpreting schools have never been conducted. 


\section{Conclusion}

By comparing and contrasting the interpreting pedagogy of higher institutions in China and western countries, the first research outcome is to graft their combined strengths into the new ICC model. There is an expectation to design new courses with contents and exercises highlighting interpreting skills, national value, expertise of the subject matters, professional ethics and image, as well as practical assessment. This being so, the teaching and learning objectives should be reviewed and revised according to international standards and benchmarking with major interpreting schools. This proposed ICC model is a recombination of the most essential elements that fit into the national policy. It corresponds to the needs of the new era in China to uplift China's cultural soft power and international discourse rights with the ultimate purpose of contributing to the realization of the "Chinese dream" ${ }^{[8]}$.

The second outcome is to incorporate the most up-to-date interpreting methodology and professional requirements to cultivate students with intercultural communication competency and international competitiveness by means of strengthening curriculum design for interpreting in terms of professionalism, professional knowledge, and professional standards.

\section{Disclosure statement}

The authors declare that there is no conflict of interest.

\section{References}

[1] 2016, Interview with Xu Jialu. December 9, 2016.

[2] 2017, Annual China Language Industry Report: China National Committee for Translation 2017.

[3] 2017, 19th National Congress of the Communist Party of China 2017 Report. China Daily Information Co (CDIC).

[4] Liu M, 2003, Translation Teaching: Practice and Theory, China Translation and Publishing Corporation, Chinese Taiwan.

[5] Liao Q, 2004, The Subject Setting and Development of Translation Studies. Chinese Translators Journal, 25(4): 36-37.

[6] Jiang QX, Cao J, 2006, A Brief Review of Present T \& I Education: Analysis and Suggestions. Chinese Translators Journal, 25(5): 8-13.

[7] Zhong WH, Mu L, 2008, Modelling the Training of Professional Translators and Interpreters: Exploration and Practice. Foreign Languages in China, 5(6): 4-14.

[8] Tsang D, 2016, The Proceedings of Globalization: Challenges for Translators and Interpreters, Innovating Translation Pedagogy How to Maximize Teaching Effectiveness while Meeting with Students' Needs and Desire. American Academic Press, Salt Lake, 98-105. 